\title{
Amiodarone-Induced Cirrhosis of Liver: What Predicts Mortality?
}

\author{
Nasir Hussain, Anirban Bhattacharyya, and Suartcha Prueksaritanond \\ Department of Internal Medicine, Saint Joseph Hospital, Resurrection Health Care, 2900 North Lake Shore Drive, \\ Chicago, IL 60657, USA
}

Correspondence should be addressed to Nasir Hussain; connect2nasir@gmail.com

Received 18 January 2013; Accepted 11 February 2013

Academic Editors: A. Bobik, C. Hassager, and B. Strasberg

Copyright (C) 2013 Nasir Hussain et al. This is an open access article distributed under the Creative Commons Attribution License, which permits unrestricted use, distribution, and reproduction in any medium, provided the original work is properly cited.

Introduction. Amiodarone has been used for more than 5 decades for the treatment of various tachyarrhythmias and previously for the treatment of refractory angina. There are multiple well-established side effects of amiodarone. However, amiodaroneinduced cirrhosis (AIC) of liver is an underrecognized complication. Methods. A systematic search of Medline from January 1970 to November 2012 by using the following terms, amiodarone and cirrhosis, identified 37 reported cases of which 30 were used in this analysis. Patients were divided into 2 subsets, survivors versus nonsurvivors, at 5 months. Results. Aspartate aminotransferase was significantly lower $(P=0.03)$ in patients who survived at 5-months (mean $103.33 \mathrm{IU} / \mathrm{L}$ ) compared to nonsurvivors (mean 216.88 IU/L). There was no statistical difference in the levels of prothrombin time, total bilirubin, alanine aminotransferase, alkaline phosphatase, gamma-glutamyl transpeptidase, cumulative dose, and latency period between the two groups. The prevalence of DM, HTN, HLD, CAD, and CHF was similar in the two groups. None of the above-mentioned variables could be identified as a predictor of survival at 5 months. Conclusion. AIC carries a mortality risk of $60 \%$ at 5 months once the diagnosis is established. Further prospective studies are needed to identify predictors of AIC and of mortality or survival in cases of AIC.

\section{Introduction}

Amiodarone has been used since the 1960s for the management of various tachyarrhythmias and in the past for refractory angina. There are multiple reported and well-established side effects of amiodarone therapy such as effects on the thyroid, skin, lungs, nerves, and cornea.

The effect of amiodarone on the liver resulting in hepatotoxicity is a recognized complication of amiodarone, but this hepatotoxicity leading to cirrhosis of the liver is unfortunately an underrecognized side effect. Little has been written on amiodarone-induced cirrhosis (AIC) of the liver due to its rarity [1-4]. The purpose of this paper is to review what we know so far about AIC of the liver.

\section{Materials and Methods}

2.1. Selection of Studies. A systematic search of Medline from January 1970 to November 2012 by using the following terms, amiodarone and cirrhosis, was performed; 37 reported cases were identified (Table 1) of which 30 were used in this analysis. We also searched the reference lists of all reported cases to identify citations that were not identified during the initial search. Data that were extracted for each patient included age, gender, latency period in years, whether $\geq 200 \mathrm{mg} /$ day amiodarone dosage was used (it is thought that low-dose amiodarone has lesser side effects), cumulative dose, presence or absence of hypertension (HTN), diabetes (DM), hyperlipidemia (HLD), coronary artery disease (CAD), congestive heart failure (CHF), values of bilirubin, aspartate transaminase (AST), alkaline phosphatase (ALK $\mathrm{P})$, albumin, alanine transaminase (ALT), and prothrombin time. The outcomes in terms of survival or mortality at 5 months were used. This specific timeline was selected because more than $50 \%$ of patients in these case reports died within 5 months after the diagnosis was established. Not all of the studies we found had all these data; however, they were included if the outcome was provided. In some 


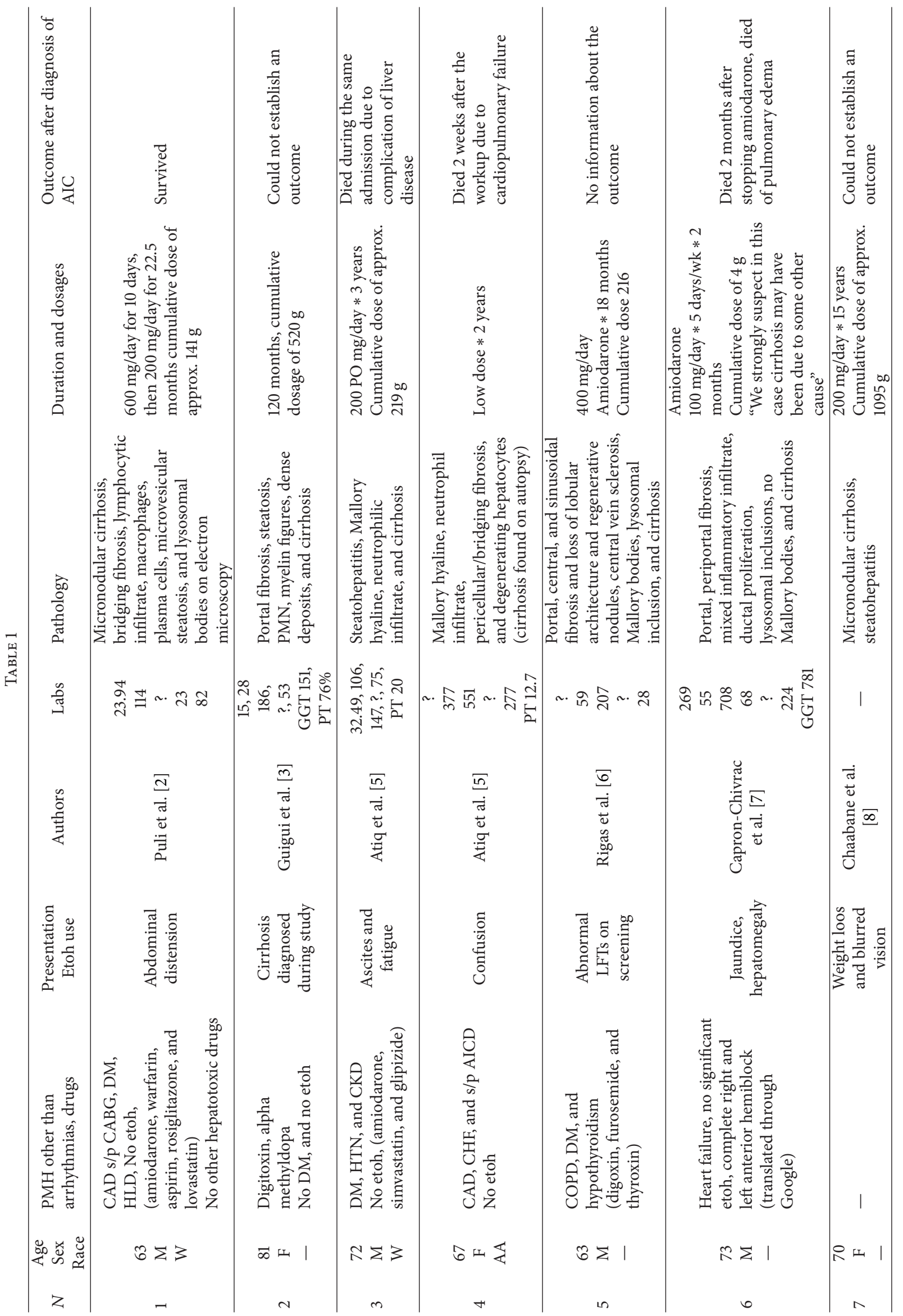




\begin{tabular}{|c|c|c|c|c|c|c|}
\hline 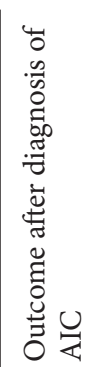 & 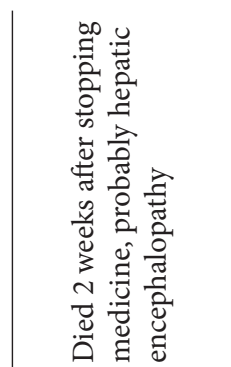 & 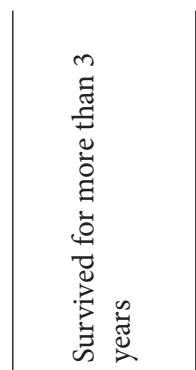 & 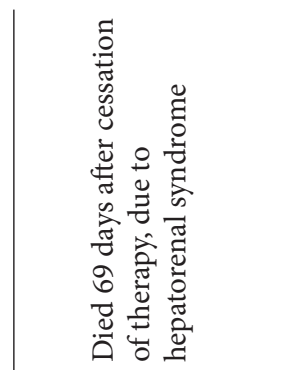 & 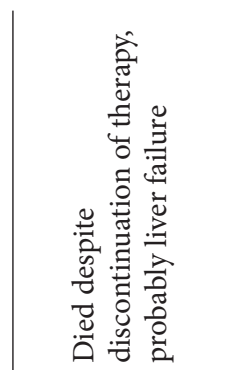 & 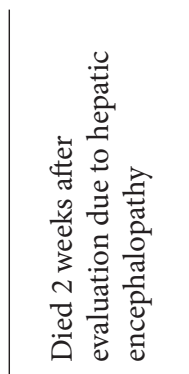 & 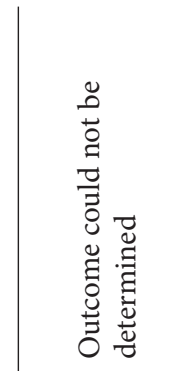 \\
\hline 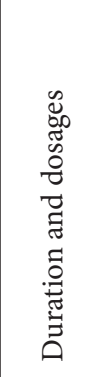 & 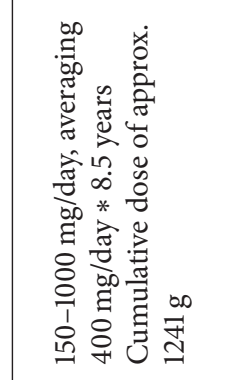 & 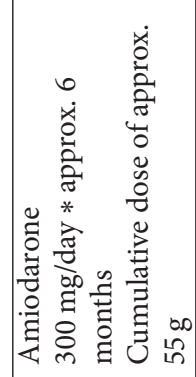 & 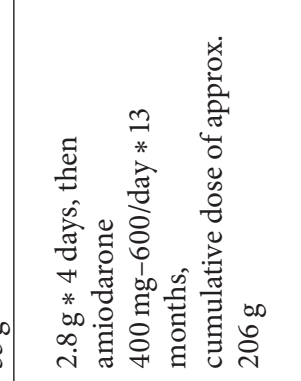 & 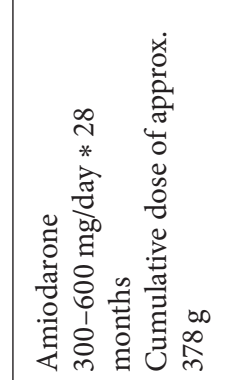 & 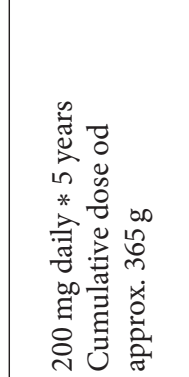 & 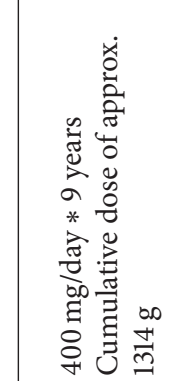 \\
\hline 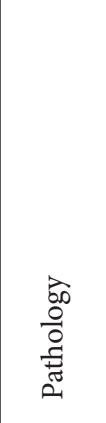 & 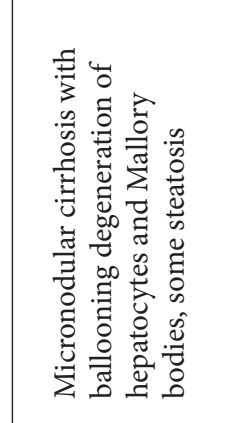 & 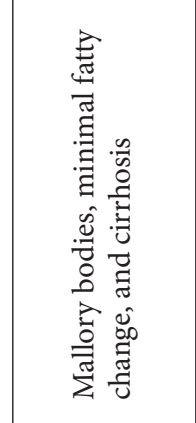 & 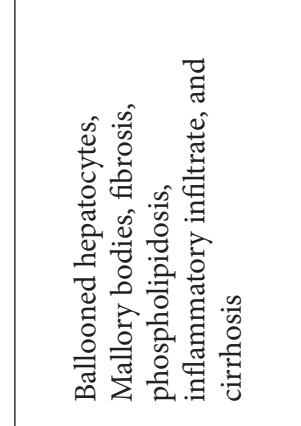 & 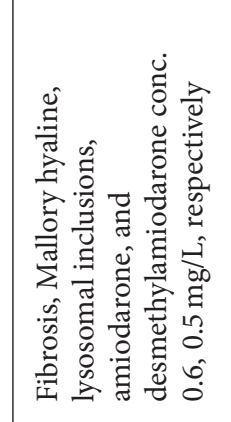 & 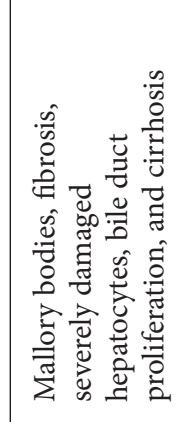 & 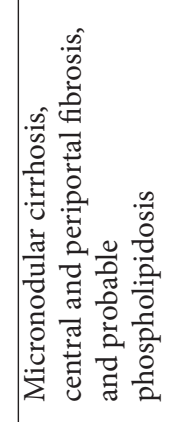 \\
\hline స్త్ర & m & $\underset{m}{\mid} \sim$. & $\approx$ すิ & 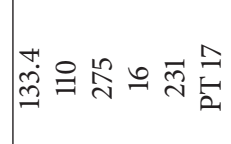 & $=$ 㫕 & 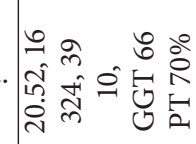 \\
\hline $\begin{array}{l}\text { 号 } \\
\text { 䒧 }\end{array}$ & $\begin{array}{l}\sigma \\
a \\
0 \\
0 \\
\vdots \\
0 \\
0 \\
0\end{array}$ & $\begin{array}{l}\sigma \\
a \\
0 \\
0 \\
\vdots \\
0 \\
0 \\
0\end{array}$ & 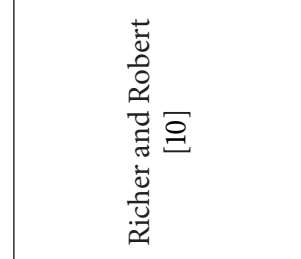 & 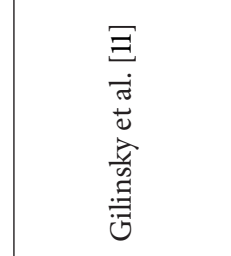 & 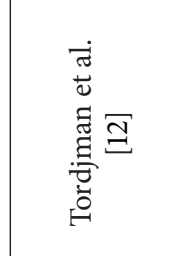 & 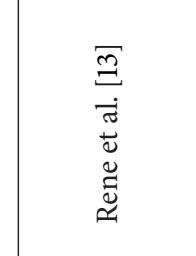 \\
\hline 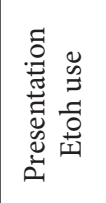 & 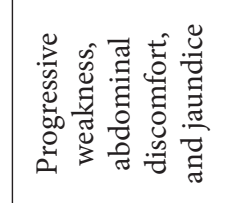 & 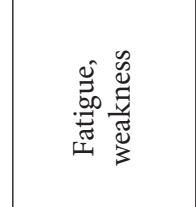 & 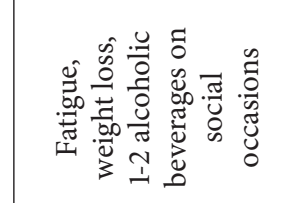 & 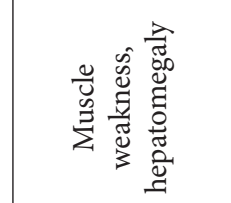 & 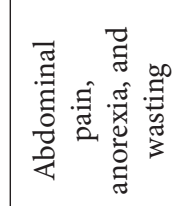 & 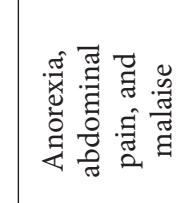 \\
\hline 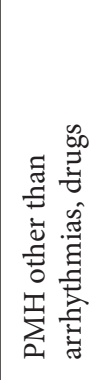 & 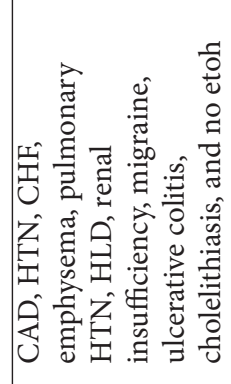 & 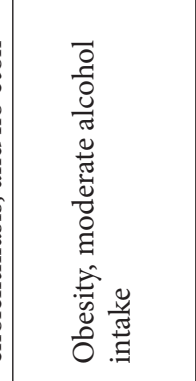 & 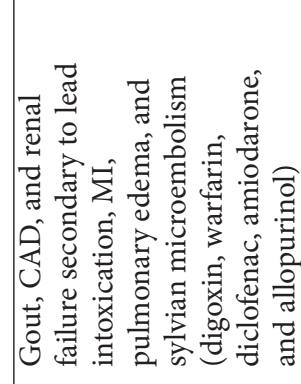 & 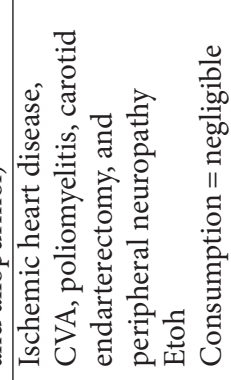 & 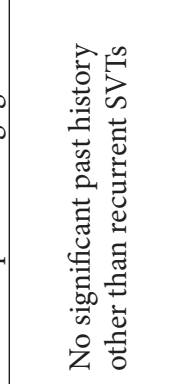 & I \\
\hline 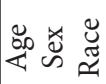 & $\sigma \Sigma$ & $\curvearrowright \Sigma 1$ & $\forall \Sigma \mid$ & $\Delta \Sigma 1$ & $\stackrel{2}{n}=1$ & 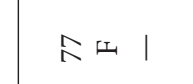 \\
\hline & & & 으 & & $\mathcal{E}$ & 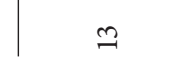 \\
\hline
\end{tabular}




\begin{tabular}{|c|c|c|c|c|c|c|}
\hline 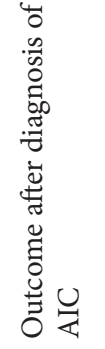 & 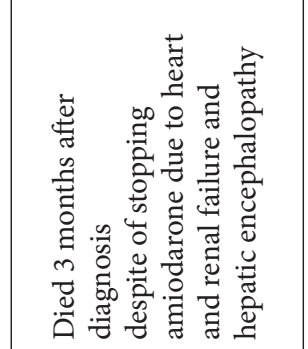 & 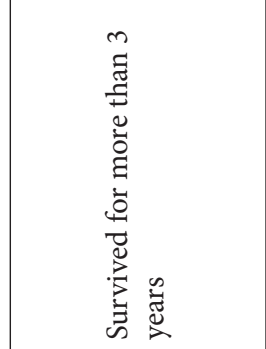 & 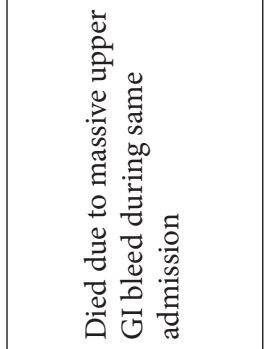 & 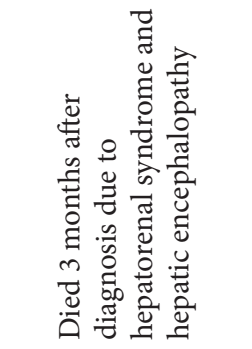 & 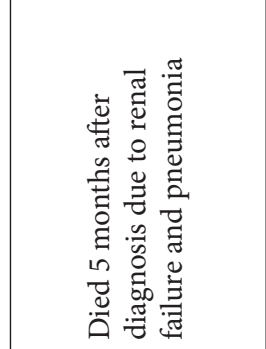 & 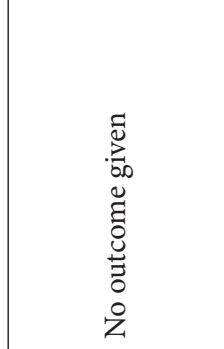 \\
\hline 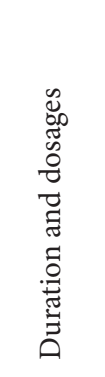 & 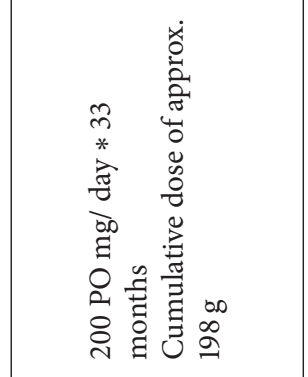 & 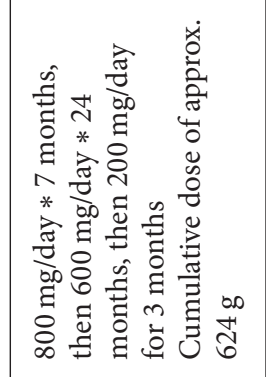 & 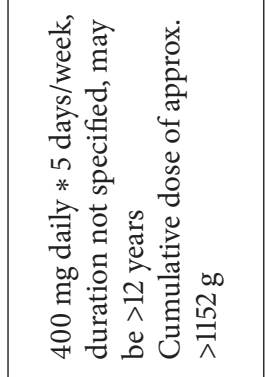 & 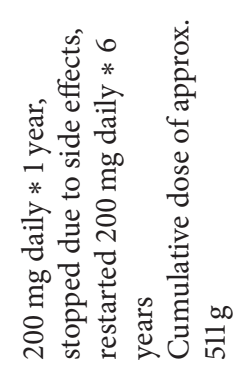 & 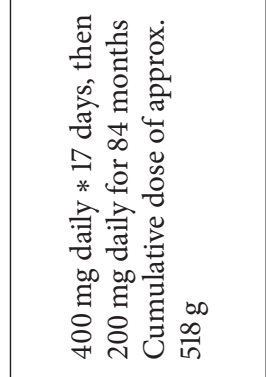 & 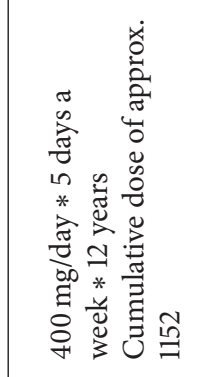 \\
\hline $\begin{array}{l}\text { के } \\
\frac{0}{0} \\
0 \\
\frac{1}{\pi} \\
0\end{array}$ & 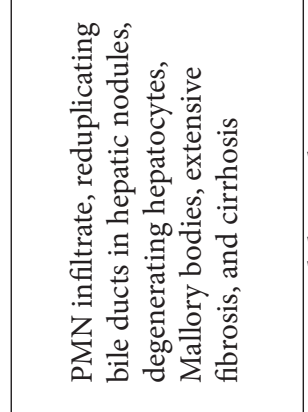 & 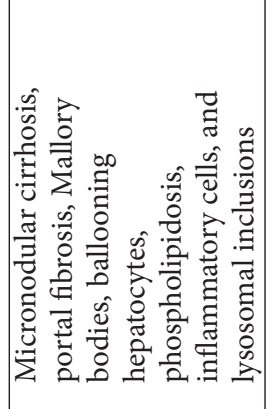 & 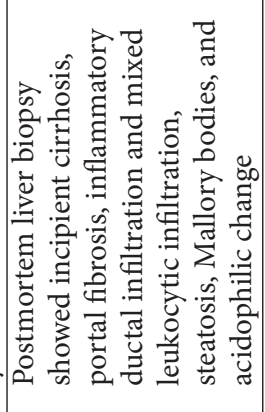 & 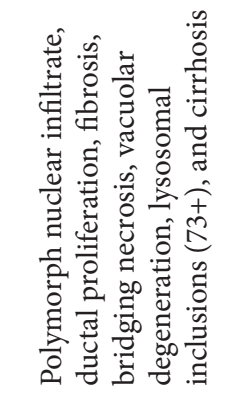 & 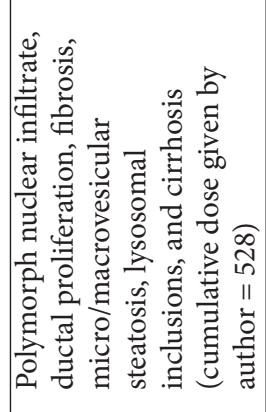 & 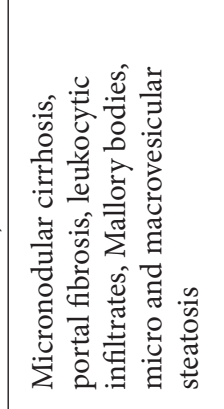 \\
\hline 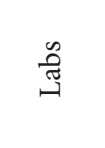 & 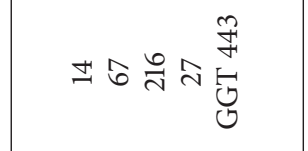 & . 웜 용 n. n. & 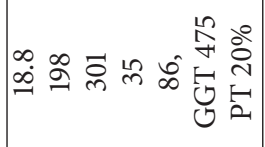 & 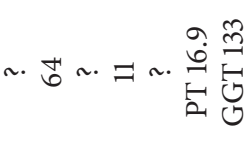 & 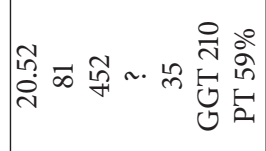 & 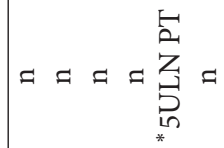 \\
\hline 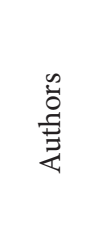 & 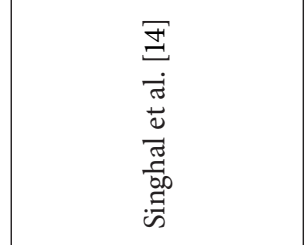 & 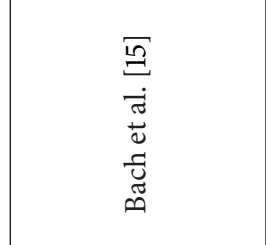 & 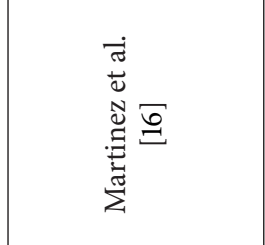 & 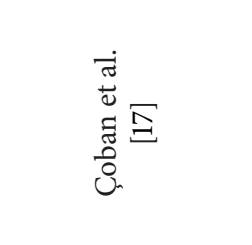 & 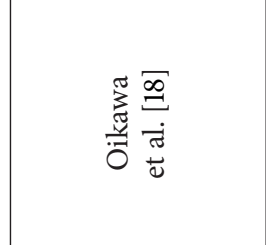 & 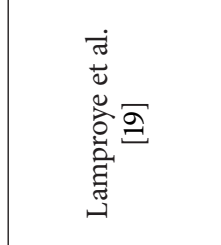 \\
\hline 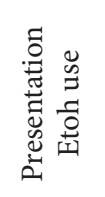 & 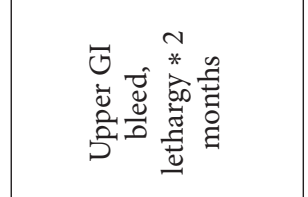 & 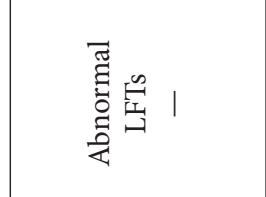 & 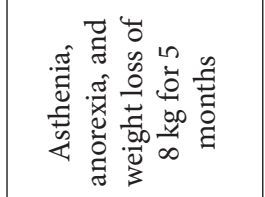 & 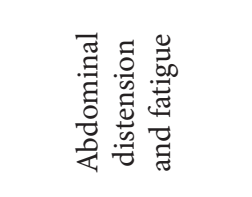 & 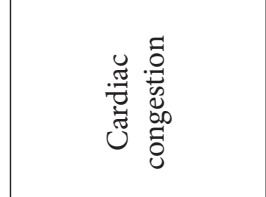 & 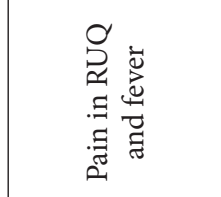 \\
\hline 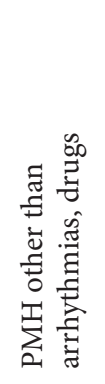 & 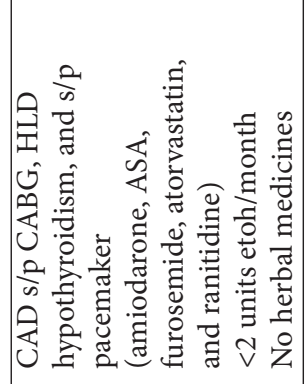 & 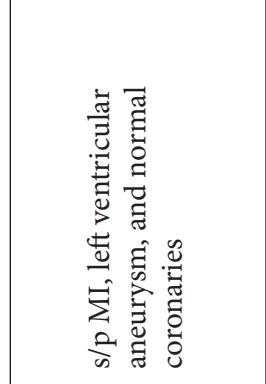 & 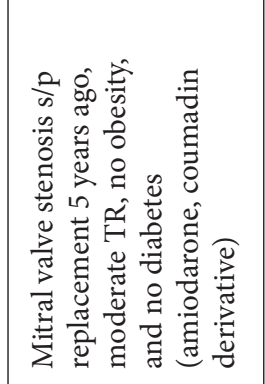 & 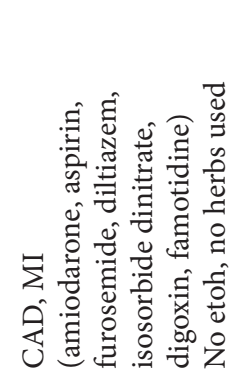 & 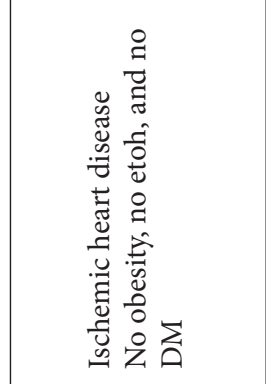 & 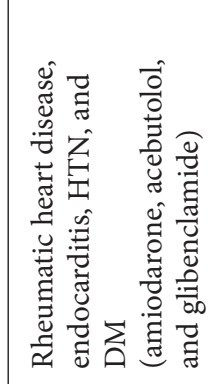 \\
\hline 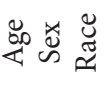 & $\curvearrowright \Sigma 1$ & 㘦 | & ஜ⼭ | & $\stackrel{\infty}{i} \Sigma \mid$ & $\infty \sum 1$ & 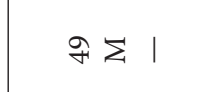 \\
\hline & - & 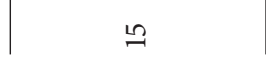 & $\mathscr{1}$ & $\triangleq$ & $\stackrel{\infty}{\stackrel{0}{2}}$ & 2 \\
\hline
\end{tabular}




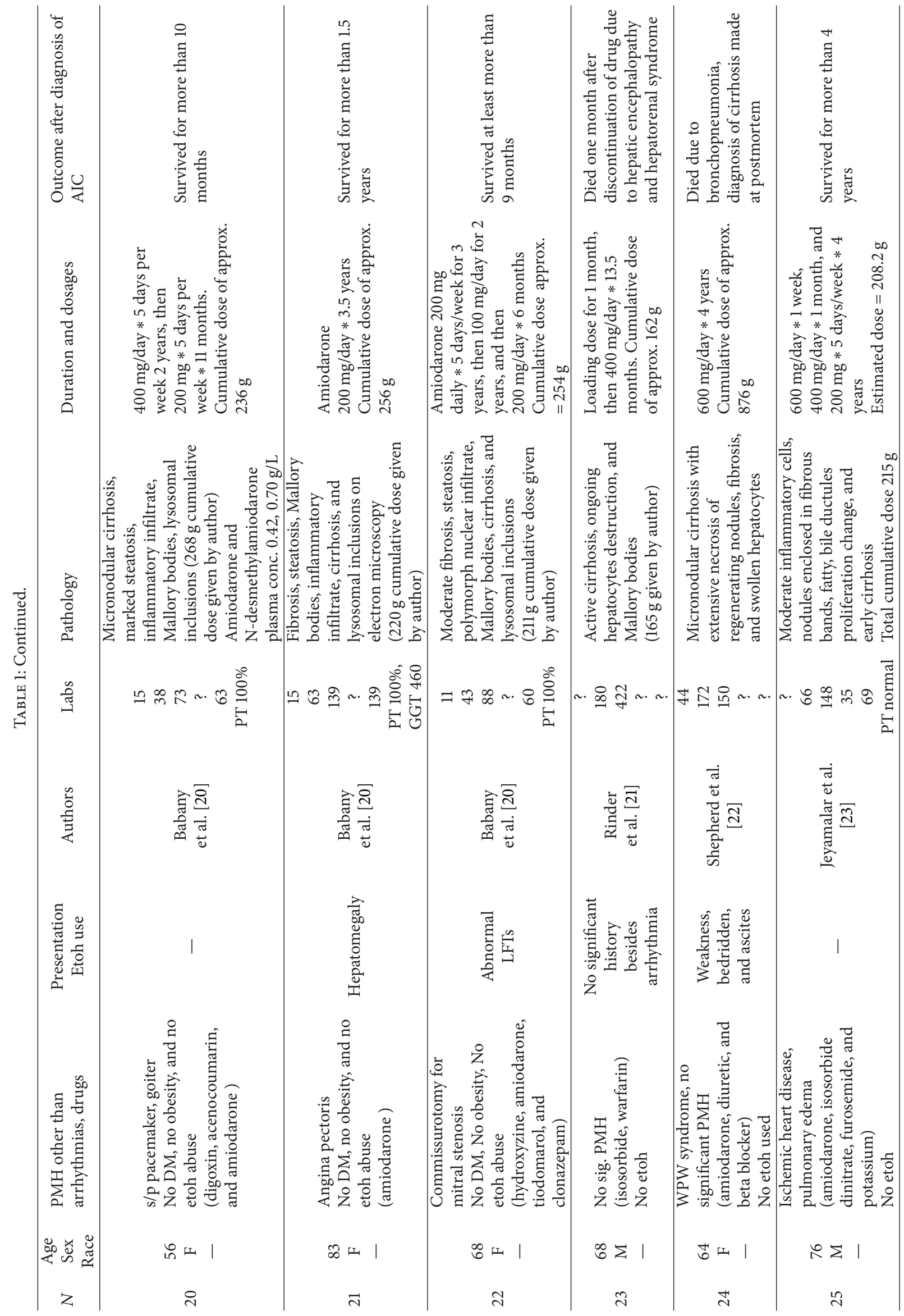




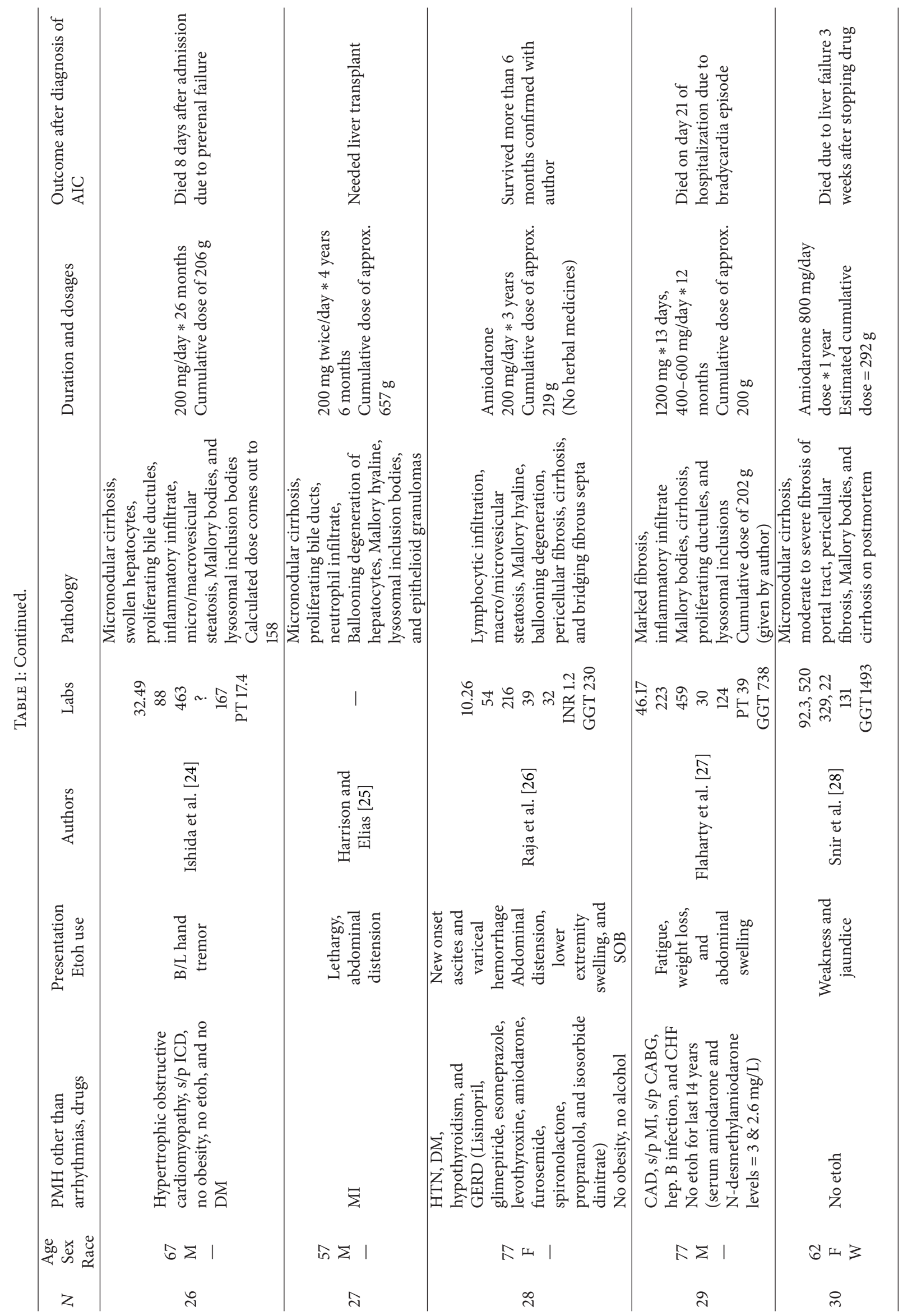




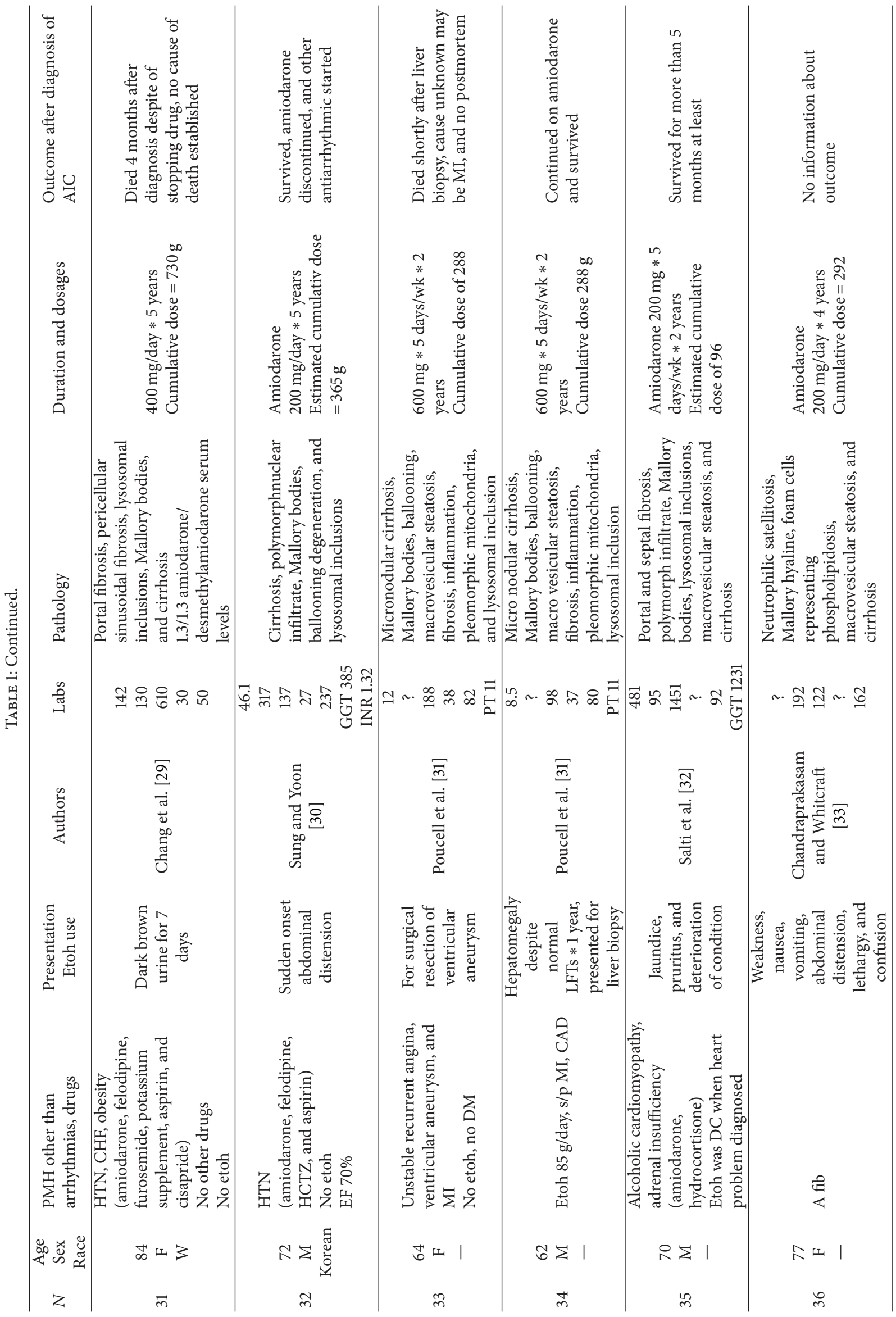




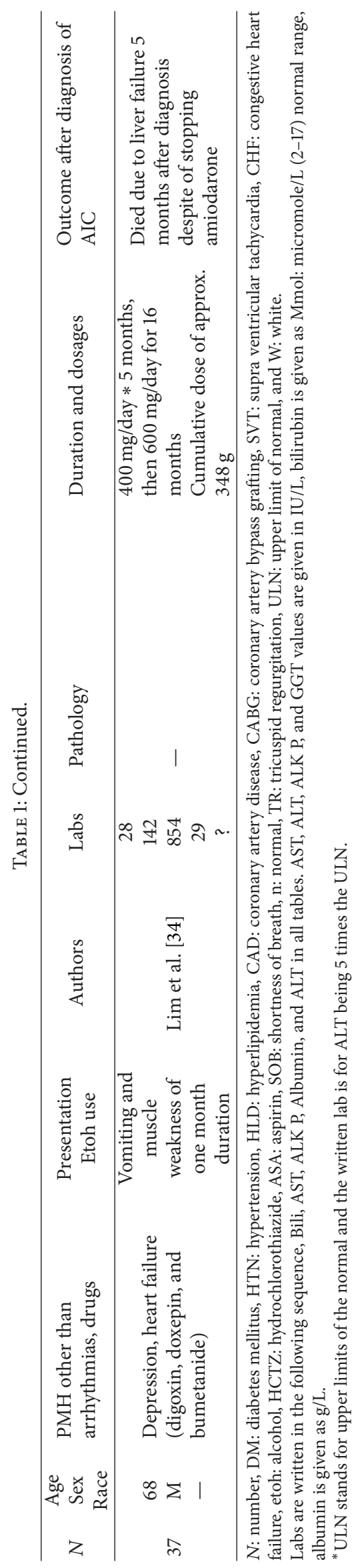


cases, the outcome was not available, authors were contacted, and the outcome was determined. Those cases, for which outcome could not be determined, were excluded from the final analysis. Of seven cases that were excluded from the final analysis, one case had indeterminate cause of cirrhosis and for the rest of cases, outcome could not be established. Some authors provided cumulative doses for amiodarone. If total cumulative dose was not given, a formula (cumulative dose in grams $=365 *$ no. of years $*$ total daily dose $/ 1000$ ) was used to estimate the final cumulative doses, with an assumption that the patient had been $100 \%$ compliant with the medicine.

Prothrombin time for some cases was given as percentage activity rather than in seconds. We could not find any convertor for percentage activity to seconds (which is a normally reported unit). For cases in which prothrombin time was reported as a percentage prothrombin activity, values were not used in this analysis.

2.2. Statistical Analysis. Of 37 cases analyzed, outcome was available only for 31 cases. One case had indeterminate cause of cirrhosis and was excluded, and 30 cases were used for our analysis.

Survival at 5 months determined the patient subset and common pathophysiologic factors like DM, HTN, HLD, $\mathrm{CAD}$, and CHF; lab values comprising of prothrombin time, total bilirubin, AST, ALT, ALK P, and GGT were compared between these two subsets. Logistic regression was used for comparing continuous independent variables, and chi-square test was used for comparing categorical variables. When the expected frequency was less than five, Fisher's exact test was used for categorical variables. Cox proportional hazards ratios were employed in determining prognosis. All statistical tests were two tailed with significance set at 95\% level $(P<$ 0.05). STATA 11 IC software was used for statistical analysis.

\section{Results}

AST was significantly lower $(P=0.03)$ in patients who survived at 5 months (mean 103.33 IU/L) compared to nonsurvivors (mean 216.88 IU/L). AST levels overall were raised in both groups and ranged between $64 \mathrm{IU} / \mathrm{L}$ and $734 \mathrm{IU} / \mathrm{L}$ (Tables 2 and 3). There was no significant difference in the levels of prothrombin time, total bilirubin, ALT, ALK P, and GGT between the two groups. The prevalence of DM, HTN, HLD, CAD, and CHF was similar in these two groups. Mean cumulative dose in cases of AIC was $280 \mathrm{~g}$ with a median latency period of 2.92 years and was statistically nonsignificant.

The risk of dying at 5 months was marginally higher in patients with high aspartate aminotransferase. Hazard ratio for death is 1.003 (95\% CI ranging between 1.001 and 1.006). This finding was statistically significant $(P=0.03)$ (Table 3$)$. Prothrombin time, total bilirubin, ALT, ALK P, GGT, and coexistence of DM, HTN, HLD, CAD, and CHF did not predict survival. Results are summarized in Tables 2 and 3.

Median age at the time of diagnosis of AIC was 68 years for all cases, 69.5 among survivors, and 67.5 among nonsurvivors. Most cases of AIC were observed among females though most who died were males.

\section{Discussion}

4.1. Pathogenesis of AIC. Amiodarone is a lipophilic agent [5] and tends to accumulate in lipid-laden organelles such as the liver. Amiodarone causes liver damage by different pathogenic mechanisms, one of which may include phospholipidosis. There are two different mechanisms by which amiodarone causes phospholipidosis.

(I) Amiodarone and its metabolites (N-desmethylamiodarone) accumulate in lysosomes of hepatocytes, bile duct epithelium, and kupffer cells and leads to inhibition of phospholipase A1 and A2 $[35,36]$, which thereby inhibits removal of lysosomal lipids and leads to phospholipidosis.

(II) Amiodarone binds to phospholipids in lysosomes and forms a nondigestible complex $[37,38]$, which leads to phospholipidosis.

The exact mechanism of phospholipidosis-induced liver damage is unclear. Phospholipidosis has been reported to occur within two months of starting amiodarone therapy $[6,7]$. Phospholipidosis occurs in a much larger percentage of patients receiving amiodarone [5] than actual hepatocellular damage ( $1 \%$ to $3 \%$ ), which suggests that phospholipidosis may or may not have a role in the pathogenesis of AIC. In fact, development of phospholipidosis is considered a marker for accumulation of amiodarone [4] rather than a marker of hepatotoxicity.

Leakage $[3,4,39,40]$ of proteolytic enzymes from abnormal lysosomes represents another pathogenic mechanism of amiodarone-induced liver damage. Leakage of proteolytic enzymes may contribute to the elevation of aminotransferases and may over time lead to hepatic necrosis, fibrosis, and eventually cirrhosis.

Immunologic mechanisms may be involved in pathogenesis in instances of amiodarone-induced acute hepatitis in patients with positive Coombs' test [41].

Amiodarone-induced inhibition of cellular respiration is another possible pathogenic mechanism for amiodaroneinduced liver damage. Impairment of mitochondrial $\beta$-oxidation and uncoupling of oxidative phosphorylation leads to the formation of reactive oxygen species, which in turn has a role in the development of AIC [42-44].

4.2. Pathology. On histologic examination of biopsy samples obtained from amiodarone-induced cirrhotic patients; leukocytic infiltrate and strikingly high Mallory's hyaline along with other usual pathologic findings of cirrhosis are noted. High Mallory's hyaline or Mallory's bodies are suggestive of AIC.

Mallory's hyaline is an eosinophilic inclusion made up of intermediate keratin filaments. Mallory's hyaline is not specific for AIC and may be seen in primary biliary cirrhosis, alcoholic cirrhosis or hepatitis, nonalcoholic cirrhosis, hepatocellular cancer, morbid obesity, and some other conditions. Mallory hyaline in AIC is present in zone 1 of acinus, whereas in alcoholic liver disease they are located usually in zone 3 [4].

Histologic findings in patients with amiodarone-induced hepatic damage are similar to those caused by alcohol $[4,45]$. 
TABLE 2: Characteristics of reported cases.

\begin{tabular}{|c|c|c|c|c|}
\hline & All cases, $N=30$ & $\begin{array}{c}\text { Survivors } \\
N=12\end{array}$ & $\begin{array}{l}\text { Nonsurvivors at } 5 \text { months } \\
\qquad N=18\end{array}$ & $P$ \\
\hline Median age (years) & $68(56-85)$ & $69.5(56-83)$ & $67.5(58-85)$ & 0.84 \\
\hline Male/female & $18 / 12$ & $7 / 5$ & $11 / 7$ & 1.00 \\
\hline Diabetes & $N=3$ & 2 & 1 & 0.23 \\
\hline HTN & $N=7$ & 2 & 5 & 1.00 \\
\hline Hyperlipidemia & $N=5$ & 2 & 3 & 1.00 \\
\hline CAD & $N=16$ & 5 & 11 & 0.26 \\
\hline $\mathrm{CHF}$ & $N=11$ & 3 & 8 & 0.39 \\
\hline $\begin{array}{l}>200 \mathrm{mg} /<200 \mathrm{mg} \\
\text { Amiodarone dose given }\end{array}$ & $18 / 12$ & $5 / 7$ & $13 / 5$ & 0.33 \\
\hline Latency period & $2.92(0.5-12)$ & $3.06(0.5-5.5)$ & $2.54(1-12)$ & 0.45 \\
\hline Cumulative dose & $279.92(55-1241)$ & $279.92(55-657)$ & $465(165-1241)$ & 0.07 \\
\hline Prothrombin time & $16.76(11-39)$ & $13.68(11-17)$ & $18.92(11-39)$ & 0.08 \\
\hline Bilirubin (micromole/liter) & $55.73(9-481)$ & $71.67(9-481)$ & $46.16(12-142)$ & 0.53 \\
\hline AST & $177.58(64-734)$ & $103.33(38-317)$ & $216.88(64-734)$ & 0.03 \\
\hline ALK P & $352.96(73-1451)$ & $331.5(73-1451)$ & $365.59(119-854)$ & 0.78 \\
\hline Albumin & $28(11-39)$ & $31(23-39)$ & $26.91(11-38)$ & 0.32 \\
\hline ALT & $134.59(32-781)$ & $92.1(32-237)$ & $170(35-781)$ & 0.16 \\
\hline GGT & 569 (133-1493) & $640.33(230-1231)$ & $538.43(133-1493)$ & 0.74 \\
\hline
\end{tabular}

$N$ refers to the number of patients in each group. Not all studies had data on all variables.

Median values given for latency period, and for all other variables, mean values are given.

The complete pathologic spectrum of alcoholic like liver injury due to amiodarone includes micro- and macrovesicular steatosis, steatonecrosis, mega mitochondria, portal inflammation, fibrosis, and cirrhosis. Amiodarone-associated epithelloid granulomas have also been reported [8].

Presence of phospholipids laden lamellar lysosomal inclusion bodies on electron microscopy $[1,4,37]$ is another characteristic pathologic finding of AIC of liver. Yap et al. observed that amiodarone-induced lysosomal inclusions developed in nearly $100 \%$ of patients at a period of 2 weeks [46].

4.3. Diagnostic Workup. AIC is a diagnosis of exclusion. Extensive workups are normally done to exclude other diagnoses including viral etiology, Wilson's disease, hemochromatosis, alpha 1 antitrypsin deficiency, alcoholic hepatitis, congestive liver damage, autoimmune liver pathologies, and hepatitis due to other drugs and toxins. There is no specific diagnostic lab test for AIC of the liver.

Furthermore, there is no specific imaging characteristic for AIC of the liver although sometimes increased liver density may be noted on a noncontract CT scan of liver. Increased liver density is thought to be secondary to increased iodine content in the liver. Amiodarone has two atoms of iodine that constitute $37 \%$ of molecular weight of the drug. Enhanced density due to amiodarone is reversible upon discontinuation of amiodarone [47].

Diagnosis of AIC is usually based on liver biopsy. Mallory hyaline and lamellar lysosomal inclusions are typical of amiodarone-induced liver damage.

4.4. Presentation. Amiodarone-induced liver damage may present as Reye's syndrome in kids [9] and may present as asymptomatic elevation of liver enzymes in adults. Asymptomatic liver enzyme elevation occurs in $25 \%$ of the population treated with amiodarone [1] and is usually reversible upon discontinuation of therapy [45]. Normalization of liver enzymes may take place anywhere from three weeks to nine months [48]. Symptomatic hepatic dysfunction occurs in less than $1 \%$ of the population treated with amiodarone and includes acute and chronic liver injuries. Acute liver injury includes acute hepatitis (idiosyncratic reaction may be involved in pathogenesis), whereas chronic liver injury includes steatosis (macro and microvesicular steatosis) and cirrhosis.

\section{General Discussion}

Amiodarone is an iodinated benzofuran derivative, lipophilic drug with a half-life of 35-110 days and a very large volume of distribution (VD). Amiodarone comes as number eight in drugs that cause drug-related hepatic fatalities [9]. Major metabolite of amiodarone, $\mathrm{N}$-desmethylamiodarone, is not only pharmacologically active but has a longer elimination half-life and a larger VD than the parent drug [1, 10, 49-51]. Amiodarone and N-desmethylamiodarone may be detected even months after stopping the drug [51] as amiodarone accumulates in lipid reservoirs and is released slowly from these reservoirs. Due to this storage mechanism, amiodarone concentration in liver may be as high as 500-fold of serum level [52]. Based on these facts, damaging effects of amiodarone may persist up to one year after complete discontinuation of therapy [1]. Since amiodarone is mainly metabolized in the liver, any damage to the liver from any cause would hamper amiodarone metabolism and lead to a vicious cycle 
TABLE 3: Prognostic indicators of 5-month survival.

\begin{tabular}{lccc}
\hline & $\begin{array}{c}\text { Hazard } \\
\text { ratio }\end{array}$ & $\begin{array}{c}95 \% \text { Confidence } \\
\text { interval }\end{array}$ & $P$ \\
\hline Age & 0.99 & $(0.94-1.05)$ & 0.80 \\
Sex & 0.90 & $(0.34-2.37)$ & 0.83 \\
Diabetes & 0.40 & $(0.05-3.08)$ & 0.32 \\
HTN & 1.34 & $(0.43-4.10)$ & 0.62 \\
Hyperlipidemia & 1.09 & $(0.29-4.03)$ & 0.90 \\
CAD & 1.49 & $(0.51-4.36)$ & 0.46 \\
CHF & 1.74 & $(0.52-5.80)$ & 0.36 \\
$>$ 200 mg/ <200 mg & & & \\
Amiodarone dose & 1.35 & $(0.48-3.84)$ & 0.56 \\
given & & & \\
Latency period & 1.12 & $(0.90-1.38)$ & 0.33 \\
Cumulative dose & 1.001 & $(0.999-1.003)$ & 0.09 \\
Prothrombin time & 1.04 & $(0.97-1.11)$ & 0.36 \\
Bilirubin & & $(0.99-1.00)$ & 0.45 \\
(micromole/liter) & 0.998 & $(1.001-1.006)$ & $\mathbf{0 . 0 3}$ \\
AST & 1.003 & $(0.999-1.001)$ & 0.98 \\
ALK P & 1.000 & $(0.91-1.09)$ & 0.89 \\
Albumin & 0.99 & $(0.999-1.005)$ & 0.21 \\
ALT & 1.002 & $(0.998-1.002)$ & 0.87 \\
GGT & 1.000 & &
\end{tabular}

Not all studies had data on all the variables.

of accumulation of amiodarone and further amiodaroneinduced hepatic damage [53].

Why some patients develop cirrhosis or hepatic damage as a side effect of amiodarone is not entirely clear. It has been suggested that differing sensitivity to amiodarone toxicity in population may exist [54]. Most patients who developed AIC usually used amiodarone PO $200 \mathrm{mg}$ or more per day for more than 1-2 years. In light of the above-mentioned fact, researchers propose that the total cumulative dose of amiodarone may be important in estimating the risk of irreversible liver injury [55]. A cumulative dose of $380 \mathrm{~g}$ is suggested to associate with hepatotoxicity leading to cirrhosis [50]. Other prospective studies showed that amiodarone hepatic toxicity correlates to steady state serum levels of amiodarone rather than daily or cumulative doses [54, 56-58]. For example, if daily dosage of amiodarone during long-term therapy is reduced, despite increasing lifetime cumulative dose, the steady state serum concentration will still be reduced and thus decreasing risk of hepatotoxicity from amiodarone. Researchers have suggested that amiodarone level less than $1.5 \mathrm{mg} / \mathrm{L}$ has a minimal risk of hepatotoxicity, whereas a level above $2.5 \mathrm{mg} / \mathrm{L}$ may have a risk up to $6 \%$ for hepatotoxicity [5]. Patients with lower eject fraction may be more prone to hepatotoxic effects of amiodarone as suggested by Tisdale et al. [59]. Although it seems logical that patients with preexisting liver damage may be more prone to amiodarone-induced AIC of the liver, results by Kum et al. suggest otherwise [60].

Besides chronic liver injury due to prolonged amiodarone use, acute hepatic side effects from amiodarone intravenous loading dose have been reported and are thought to be caused by polysorbate 80 ; a solvent used in drug preparation. This form of acute hepatotoxicity usually improves with discontinuation of medication, although fatalities have been reported [61].

To prevent amiodarone-induced cirrhosis, the amiodarone should be titrated to lowest effective dose. Patients should have baseline LFTs and then periodic monitoring of LFTs while on amiodarone (at 1, 3, and 6 months and then semiannually) [62]. Studies have suggested that baseline LFTs monitoring is performed only in $44 \%$ of patients, and a follow-up testing at 6 months and 1 year is done in only $41 \%$ and $35 \%$ of patients, respectively [63]. Patients found to have asymptomatic elevation of transaminases while on amiodarone should have a thorough investigation of the cause [56]; repeated testing may be necessary before labeling diagnosis of amiodarone-induced hepatotoxicity [45]. According to some authors, discontinuation of amiodarone for liver-related toxicity may not be necessary [57]. Kum et al. noted in their study that $50 \%$ of patients with increased transaminases while on amiodarone did not improve even after 1.5 years of drug withdrawal [60]. However, most authors suggest that if aminotransferases are two times above baseline value or above three times the upper normal limit, then amiodarone either should be reduced or discontinued [58, 61, $64,65]$. Withdrawal of drug, when irreversible liver damage has already occurred, has a very little effect on restoration of liver function. Despite what is said, discontinuation of amiodarone for liver-related hepatotoxicity may not be necessary except in cases to prevent irreversible loss of liver function [11]. After discontinuation of amiodarone, monitoring period should continue for at least one year as the damaging effect of amiodarone might persist. Patients on amiodarone should be advised to avoid any potentially hepatotoxic agent to prevent additive hepatic damage. Discontinuation of amiodarone is reported to occur in nearly $20-40 \%$ of patients if changes in aminotransferases are detected during amiodarone therapy [66].

To date, the role of routine monitoring of amiodarone or its metabolite's serum levels for predicting hepatic damage is not well established. Nonetheless, there are numerous patients who may develop AIC without any abnormality in liver enzymes. Such patient population will not be detected until very late. Routine imaging may have a role in this subset of patients, but there is no study to support this.

Based on our review (Table 1), we noted that AIC is extremely rare. However, once the diagnosis is established, the mortality risk may be as high as $60 \%$ at 5 months. The most common cause of death among reported cases was due to liver- and GI-related complications. Ethnic predisposition to AIC could not be determined due to lack of the published literature. The most common symptoms reported were generalized weakness, abdominal pain, and abdominal distension.

A cumulative dose of $380 \mathrm{~g}$ has been suggested to associate with cirrhosis. By reviewing published cases, we realize that cirrhosis has been reported to occur with a cumulative dose as low as $55 \mathrm{~g}$ [9]. Why some patients with a cumulative dose of $200 \mathrm{~g}$ develop cirrhosis and others do not until cumulative dose crosses above $1000 \mathrm{~g}$ is unclear, but it does suggest that it may be a steady state concentration rather 
than cumulative dose that may be important in predicting risk of cirrhosis. The diagnosis in most patients was made by liver biopsy. Although Mallory hyaline and lysosomal inclusions are characteristic features of amiodarone-induced cirrhosis, the dilemma is that the above-mentioned pathologic characteristics may be identified in patients on amiodarone who do not have cirrhosis. Liver biopsy alone for diagnosis of AIC may not be enough. In fact, a thorough evaluation for all possible causes of cirrhosis should be done. Once all possible causes of cirrhosis have been ruled out, then only the presence of Mallory hyaline and lysosomal inclusions in cirrhotic liver may be suggestive of AIC of the liver. In all published cases, a thorough investigation for the cause of cirrhosis was carried out. In most published cases, obesity, DM, and ethanol consumption were given special attention to rule out the possibility of alcoholic and nonalcoholic steatohepatitis (NASH). Risk factors for development of amiodarone-induced hepatotoxicity and cirrhosis have not been clearly defined. Whether it is cumulative dose or steady state concentration of amiodarone that predicts risk of cirrhosis has not been determined. In most patients even after discontinuation of amiodarone, toxicity effects did not subside. Majority of patients have had amiodaronerelated hepatotoxicity before onset of cirrhosis leading to a decrease in dose or discontinuation of the drug. However, the drug was restarted for various reasons, which unfortunately lead to cirrhosis. Although AST and ALTs are said to be mainly elevated in amiodarone-related hepatotoxicity and not the ALK P or GGT [56], our analysis suggests otherwise. According to our analysis, the only statistically significant variable different among survivors versus nonsurvivors at 5 months was the level of AST at time of diagnosis of AIC. We suggest that if patients on amiodarone have a persistent increase in aminotransferases, a liver imaging and a liver biopsy should be done.

There is no treatment available for amiodarone-induced hepatotoxicity or cirrhosis besides discontinuation of the offending agent and switching to some other antiarrhythmic agent. Previously, antioxidants vitamin $\mathrm{E}$ and selenium have been tried without any success. We recommend against using antioxidants for counteracting amiodarone hepatotoxicity, as there is no strong scientific evidence for such practices.

We are aware that there are limitations in our study because of the smaller sample size, which may have affected our analysis. Future prospective studies using larger patient population may be able to identify predictors of survival in case of AIC.

\section{Conclusion}

Although amiodarone does have very serious and fatal effects on the liver, such effects are rare. With a closer monitoring and taking appropriate actions when prompted, amiodarone can be safely used on long-term basis. Further prospective studies are needed to identify predictors of AIC and of mortality or survival in cases of AIC. Role of routine imaging and biopsy of the liver in patients taking amiodarone is unclear; future studies are needed to address this issue.

\section{References}

[1] J. H. Lewis, R. C. Ranard, A. Caruso et al., "Amiodarone hepatotoxicity: prevalence and clinicopathologic correlations among 104 patients," Hepatology, vol. 9, no. 5, pp. 679-685, 1989.

[2] S. R. Puli, M. A. Fraley, V. Puli, A. B. Kuperman, and M. A. Alpert, "Hepatic cirrhosis caused by low-dose oral amiodarone therapy," American Journal of the Medical Sciences, vol. 330, no. 5, pp. 257-261, 2005.

[3] B. Guigui, S. Perrot, J. P. Berry et al., "Amiodarone-induced hepatic phospholipidosis: a morphological alteration independent of pseudoalcoholic liver disease," Hepatology, vol. 8, no. 5, pp. 1063-1068, 1988.

[4] J. H. Lewis, F. Mullick, K. G. Ishak et al., "Histopathologic analysis of suspected amiodarone hepatotoxicity," Human Pathology, vol. 21, no. 1, pp. 59-67, 1990.

[5] M. Atiq, J. C. Davis, L. W. Lamps, S. S. Beland, and J. E. Rose, "Amiodarone induced liver cirrhosis. Report of two cases," Journal of Gastrointestinal and Liver Diseases, vol. 18, no. 2, pp. 233-235, 2009.

[6] B. Rigas, L. E. Rosenfeld, and K. W. Barwick, "Amiodarone hepatotoxicity. A clinicopathologic study of five patients," Annals of Internal Medicine, vol. 104, no. 3, pp. 348-351, 1986.

[7] D. Capron-Chivrac, N. Reix, C. Quenum, and J. P. Capron, "Amiodarone hepatopathy. Study of a case and review of the literature," Gastroenterologie Clinique et Biologique, vol. 9, no. 6-7, pp. 535-539, 1985.

[8] N. B. Chaabane, O. Hellara, L. Safer et al., "Cirrhosis with increased density of the liver: amiodarone-induced hepatotoxicity," Tunisie Medicale, vol. 90, no. 6, pp. 487-488, 2012.

[9] http://livertox.nih.gov/Amiodarone.htm.

[10] M. Richer and S. Robert, "Fatal hepatotoxicity following oral administration of amiodarone," Annals of Pharmacotherapy, vol. 29 , no. 6, pp. 582-586, 1995.

[11] N. H. Gilinsky, G. W. Briscoe, and C. S. Kuo, "Fatal amiodarone hepatoxicity," American Journal of Gastroenterology, vol. 83, no. 2, pp. 161-163, 1988.

[12] K. Tordjman, I. Katz, M. Brusztyn, and T. Rosenthal, "Amiodarone and the liver," Annals of Internal Medicine, vol. 102, no. 3, pp. 411-412, 1985.

[13] J. M. Rene, J. Buenestado, B. Pais, and M. C. Pinol, "Cirrosis causada por amiodarona," Revista Espanola de Enfermedades Digestivas, vol. 87, no. 5, pp. 399-402, 1995.

[14] A. Singhal, P. Ghosh, and S. A. Khan, "Low dose amiodarone causing pseudo-alcoholic cirrhosis," Age and Ageing, vol. 32, no. 2, pp. 224-225, 2003.

[15] N. Bach, B. L. Schultz, L. B. Cohen et al., "Amiodarone hepatotoxicity: progression from steatosis to cirrhosis," Mount Sinai Journal of Medicine, vol. 56, no. 4, pp. 293-296, 1989.

[16] R. Martinez, E. Saperas, J. Vilaseca, P. Tornos, and H. Allende, "Cirrosis hepatica inducida por amiodarona," Gastroenterologia y Hepatologia, vol. 17, no. 9, pp. 482-484, 1994.

[17] Ş. Çoban, S. Köklü, H. Sencer, F. Ekiz, and N. Örmeci, "Low dose amiodarone associated cirrhosis," Journal of Gastroenterology and Hepatology, vol. 22, no. 1, pp. 140-141, 2007.

[18] H. Oikawa, C. Maesawa, R. Sato et al., "Liver cirrhosis induced by long-term administration of a daily low dose of amiodarone: a case report," World Journal of Gastroenterology, vol. 11, no. 34, pp. 5394-5397, 2005.

[19] A. Lamproye, J. Ramos, D. Larrey, and J. Belaiche, "Pseudoalcoholic hepatitis and cirrhosis caused by Amiodarone (Cordarone)," Revue Médicale de Liège, vol. 53, pp. 120-124, 1998. 
[20] G. Babany, A. Mallat, and E. S. Zafrani, "Chronic liver disease after low daily doses of amiodarone. Report of three cases," Journal of Hepatology, vol. 3, no. 2, pp. 228-232, 1986.

[21] H. M. Rinder, J. C. Love, and R. Wexler, "Amiodarone hepatotoxicity," The New England Journal of Medicine, vol. 314, no. 5, pp. 318-319, 1986.

[22] N. A. Shepherd, A. M. Dawson, P. R. Crocker, and D. A. Levison, "Granular cells as a marker of early amiodarone hepatotoxicity: a pathological and analytical study," Journal of Clinical Pathology, vol. 40, no. 4, pp. 418-423, 1987.

[23] R. Jeyamalar, R. Pathmanathan, D. Wong, and P. Kannan, "Hepatotoxicity of amiodarone," Annals of the Academy of Medicine Singapore, vol. 21, no. 6, pp. 838-840, 1992.

[24] S. Ishida, M. Sugino, T. Hosokawa et al., "Amiodarone-induced liver cirrhosis and parkinsonism: a case report," Clinical Neuropathology, vol. 29, no. 2, pp. 84-88, 2010.

[25] R. F. Harrison and E. Elias, "Amiodarone-associated cirrhosis with hepatic and lymph node granulomas," Histopathology, vol. 22, no. 1, pp. 80-82, 1993.

[26] K. Raja, S. N. Thung, M. I. Fiel, and C. Chang, "Druginduced steatohepatitis leading to cirrhosis: long-term toxicity of amiodarone use," Seminars in Liver Disease, vol. 29, no. 4, pp. 423-428, 2009.

[27] K. K. Flaharty, S. L. Chase, H. M. Yaghsezian, and R. Rubin, "Hepatotoxicity associated with amiodarone therapy," Pharmacotherapy, vol. 9, no. 1, pp. 39-44, 1989.

[28] Y. Snir, N. Pick, K. Riesenberg, I. Yanai-Inbar, H. Zirkin, and F. Schlaeffer, "Fatal hepatic failure due to prolonged amiodarone treatment," Journal of Clinical Gastroenterology, vol. 20, no. 3, pp. 265-266, 1995.

[29] C. C. Chang, M. Petrelli, J. F. Tomashefski, and A. J. McCullough, "Severe intrahepatic cholestasis caused by amiodarone toxicity after withdrawal of the drug: a case report and review of the literature," Archives of Pathology and Laboratory Medicine, vol. 123, no. 3, pp. 251-256, 1999.

[30] P. S. Sung and S. K. Yoon, "Amiodarone hepatotoxicity," Нераtology, vol. 55, no. 1, pp. 325-326, 2012.

[31] S. Poucell, J. Ireton, and P. Valencia-Mayoral, "Amiodaroneassociated phospholipidosis and fibrosis of the liver. Light, immunohistochemical, and electron microscopic studies," Gastroenterology, vol. 86, no. 5 I, pp. 926-936, 1984.

[32] Z. Salti, P. Cloche, P. Weber, G. Houssemand, and F. Vollmer, "A case of amiodarone-induced cholestatic hepatitis," Annales de Cardiologie et d'Angeiologie, vol. 38, no. 1, pp. 13-16, 1989.

[33] S. Chandraprakasam and M. Whitcraft, "Pseudo-alcoholic cirrhosis: an interesting case of amiodarone induced hepatotoxicity," The Internet Journal of Gastroenterology, vol. 11, no. 1, 2012.

[34] P. K. Lim, P. N. Trewby, G. C. A. Storey, and D. W. Holt, "Neuropathy and fatal hepatitis in a patient receiving amiodarone," British Medical Journal, vol. 288, no. 6431, pp. 1638-1639, 1984.

[35] K. Itostetler, M. Reasor, and B. W. Frazee, "Mechanisms of amiodarone toxicity: inhibition of phospholipase A," Circulation, vol. 79, p. 240, 1984.

[36] M. F. Heath, F. R. Costa-Jussa, J. M. Jacobs, and W. Jacobson, "The induction of pulmonary phospholipidosis and the inhibition of lysosomal phospholipases by amiodarone," British Journal of Experimental Pathology, vol. 66, no. 4, pp. 391-397, 1985.

[37] R. Luallmann-Rauch and G. H. Reil, "Chlorphentermineinduced lipidosis-like ultrastructural alterations in lungs and adrenal glands of several species," Toxicology and Applied Pharmacology, vol. 30, pp. 408-421, 1974.
[38] M. Pirovino, O. Muller, T. Zysset, and U. Honegger, "Amiodarone-induced hepatic phospholipidosis: correlation of morphological and biochemical findings in an animal model," Hepatology, vol. 8, no. 3, pp. 591-598, 1988.

[39] P. Yagupsky, E. Gazala, and S. Sofer, "Fatal hepatic failure and encephalopathy associated with amiodarone therapy," Journal of Pediatrics, vol. 107, no. 6, pp. 967-970, 1985.

[40] A. Vereckei, E. Fehér, I. György et al., "Possibilities of antioxidant therapy in the prevention of side effects of amiodarone," Orvosi Hetilap, vol. 132, no. 23, pp. 1265-1268, 1991.

[41] H. W. M. Breuer, W. Bossek, C. Haferland, M. Schmidt, H. Neumann, and J. Gruszka, "Amiodarone-induced severe hepatitis mediated by immunological mechanisms," International Journal of Clinical Pharmacology and Therapeutics, vol. 36, no. 6, pp. 350-352, 1998.

[42] P. Kaufmann, M. Török, A. Hänni, P. Roberts, R. Gasser, and S. Krähenbühl, "Mechanisms of benzarone and benzbromaroneinduced hepatic toxicity," Hepatology, vol. 41, no. 4, pp. 925-935, 2005.

[43] B. Fromenty, C. Fisch, G. Labbe et al., "Amiodarone inhibits the mitochondrial $\beta$-oxidation and fatty acids and produces microvesicular steatosis of the liver in mice," Journal of Pharmacology and Experimental Therapeutics, vol. 255, no. 3, pp. 13711376, 1990.

[44] B. Fromenty, C. Fisch, A. Berson, P. Letteron, D. Larrey, and D. Pessayre, "Dual effect of amiodarone on mitochondrial respiration. Initial protonophoric uncoupling effect followed by inhibition of the respiratory chain at the levels of complex I and complex II," Journal of Pharmacology and Experimental Therapeutics, vol. 255, no. 3, pp. 1377-1384, 1990.

[45] P. T. Pollak, "How toxic is amiodarone to the liver?" Journal of Gastrointestinal and Liver Diseases, vol. 19, no. 1, pp. 11-13, 2010.

[46] S. H. Yap, P. J. M. Rijntjes, H. J. Moshage, H. Croes, and P. H. $\mathrm{K}$. Jap, "Amiodarone-induced lysosomal inclusions in primary cultures of human hepatocytes," Gastroenterology, vol. 92, no. 1, pp. 272-273, 1987.

[47] S. Kojima, S. Kojima, H. Ueno, M. Takeya, and H. Ogawa, "Increased density of the liver and amiodarone associated phospholipidosis," Cardiol Res Pract, vol. 2009, Article ID 598940, 3 pages, 2009.

[48] L. Llanos, R. Moreu, A. M. Peiró et al., "Causality assessment of liver injury after chronic oral amiodarone intake," Pharmacoepidemiology and Drug Safety, vol. 18, no. 4, pp. 291-300, 2009.

[49] J. Gill, R. C. Heel, and A. Fitton, "Amiodarone. An overview of its pharmacological properties, and review of its therapeutic use in cardiac arrhythmias," Drugs, vol. 43, no. 1, pp. 69-110, 1992.

[50] P. C. Adams, M. K. Bennett, and D. W. Holt, "Hepatic effects of amiodarone," British Journal of Clinical Practice. Supplement, vol. 44, pp. 81-95, 1986.

[51] J. B. Simon, P. N. Manley, J. F. Brien, and P. W. Armstrong, "Amiodarone hepatotoxicity simulating alcoholic liver disease," The New England Journal of Medicine, vol. 311, no. 3, pp. 167-172, 1984.

[52] J. F. Brien, S. Jimmo, and F. J. Brennan, "Distribution of amiodarone and its metabolite, desethylamiodarone, in human tissues," Canadian Journal of Physiology and Pharmacology, vol. 65, no. 3, pp. 360-364, 1987.

[53] P. Lettéron, A. Sutton, A. Mansouri, B. Fromenty, and D. Pessayre, "Inhibition of microsomal triglyceride transfer protein: another mechanism for drug-induced steatosis in mice," Hepatology, vol. 38, no. 1, pp. 133-140, 2003. 
[54] N. Gluck, M. Fried, and R. Porat, "Acute amiodarone liver toxicity likely due to Ischemic hepatitis," Israel Medical Association Journal, vol. 13, no. 12, pp. 748-752, 2011.

[55] U. Klotz, "Antiarrhythmics: elimination and dosage considerations in hepatic impairment," Clinical Pharmacokinetics, vol. 46, no. 12, pp. 985-996, 2007.

[56] D. S. Pratt and M. M. Kaplan, "Evaluation of abnormal liverenzyme results in asymptomatic patients," The New England Journal of Medicine, vol. 342, no. 17, pp. 1266-1271, 2000.

[57] W. Mattar, B. Juliar, I. Gradus-Pizlo, and P. Y. Kwo, "Amiodarone hepatotoxicity in the context of the metabolic syndrome and right-sided heart failure," Journal of Gastrointestinal and Liver Diseases, vol. 18, no. 4, pp. 419-423, 2009.

[58] M. Babatin, S. S. Lee, and P. T. Pollak, "Amiodarone hepatotoxicity," Current Vascular Pharmacology, vol. 6, no. 3, pp. 228-236, 2008.

[59] J. E. Tisdale, S. L. Follin, A. Ordelova, and C. R. Webb, "Risk factors for the development of specific noncardiovascular adverse effects associated with amiodarone," Journal of Clinical Pharmacology, vol. 35, no. 4, pp. 351-356, 1995.

[60] L. C. C. Kum, W. W. L. Chan, H. H. Y. Hui et al., "Prevalence of amiodarone-related hepatotoxicity in 720 Chinese patients with or without baseline liver dysfunction," Clinical Cardiology, vol. 29, no. 7, pp. 295-299, 2006.

[61] A. E. Rätz Bravo, J. Drewe, R. G. Schlienger, S. Krähenbühl, H. Pargger, and W. Ummenhofer, "Hepatotoxicity during rapid intravenous loading with amiodarone: description of three cases and review of the literature," Critical Care Medicine, vol. 33, no. 1, pp. 128-134, 2005.

[62] P. T. Pollak and S. L. Shafer, "Use of population modeling to define rational monitoring of amiodarone hepatic effects," Clinical Pharmacology and Therapeutics, vol. 75, no. 4, pp. 342351, 2004.

[63] C. Burgess, A. Blaikie, T. Ingham, G. Robinson, and S. Narasimhan, "Monitoring the use of amiodarone: compliance with guidelines," Internal Medicine Journal, vol. 36, no. 5, pp. 289-293, 2006.

[64] P. T. Pollak and Y. D. You, "Monitoring of hepatic function during amiodarone therapy," American Journal of Cardiology, vol. 91, no. 5, pp. 613-616, 2003.

[65] P. T. Pollak, A. D. Sharma, and S. G. Carruthers, "Relation of amiodarone hepatic and pulmonary toxicity to serum drug concentrations and superoxide dismutase activity", American Journal of Cardiology, vol. 65, no. 18, pp. 1185-1191, 1990.

[66] P. J. Podrid, “Amiodarone: reevaluation of an old drug," Annals of Internal Medicine, vol. 122, no. 9, pp. 689-700, 1995. 


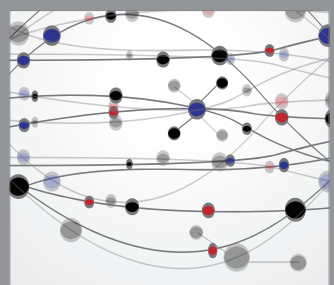

The Scientific World Journal
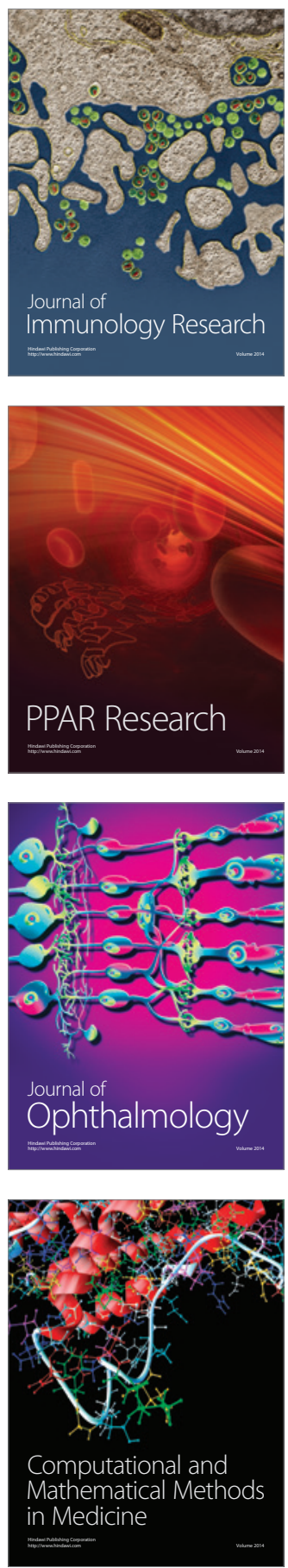

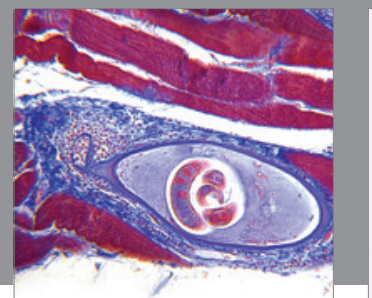

Gastroenterology

Research and Practice
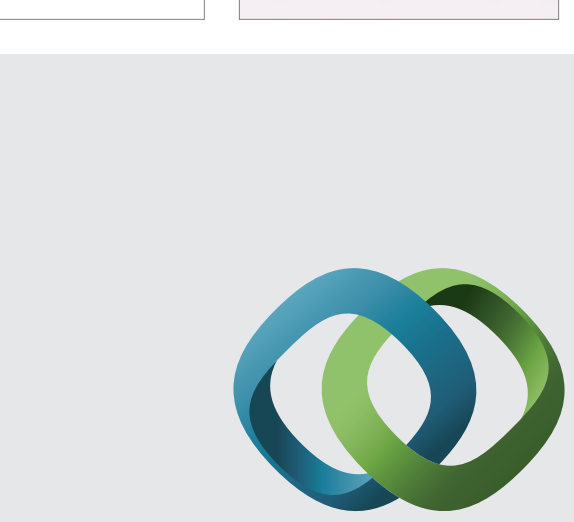

\section{Hindawi}

Submit your manuscripts at

http://www.hindawi.com
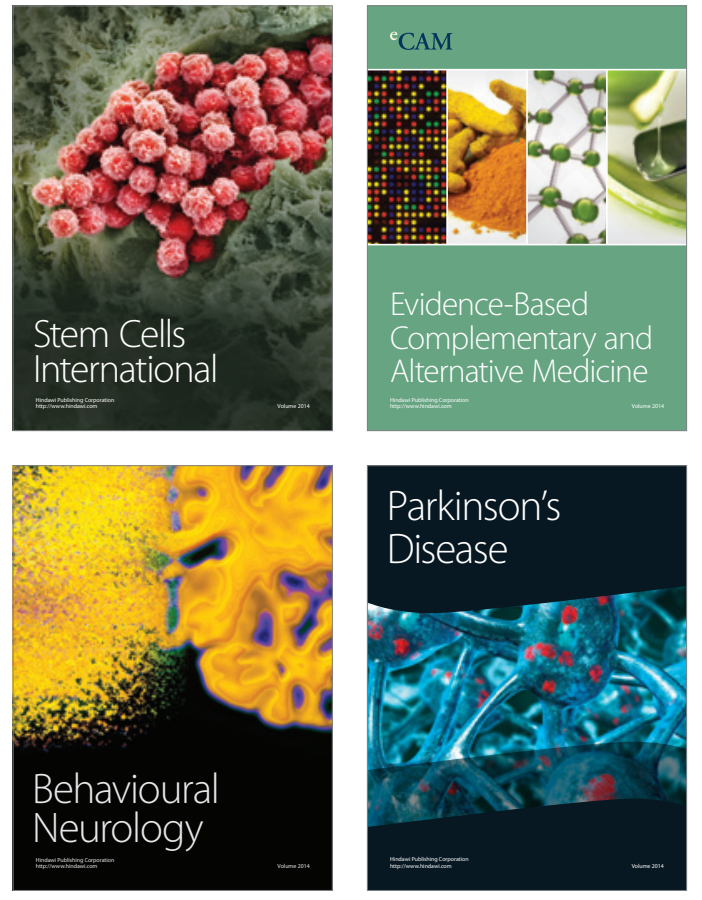
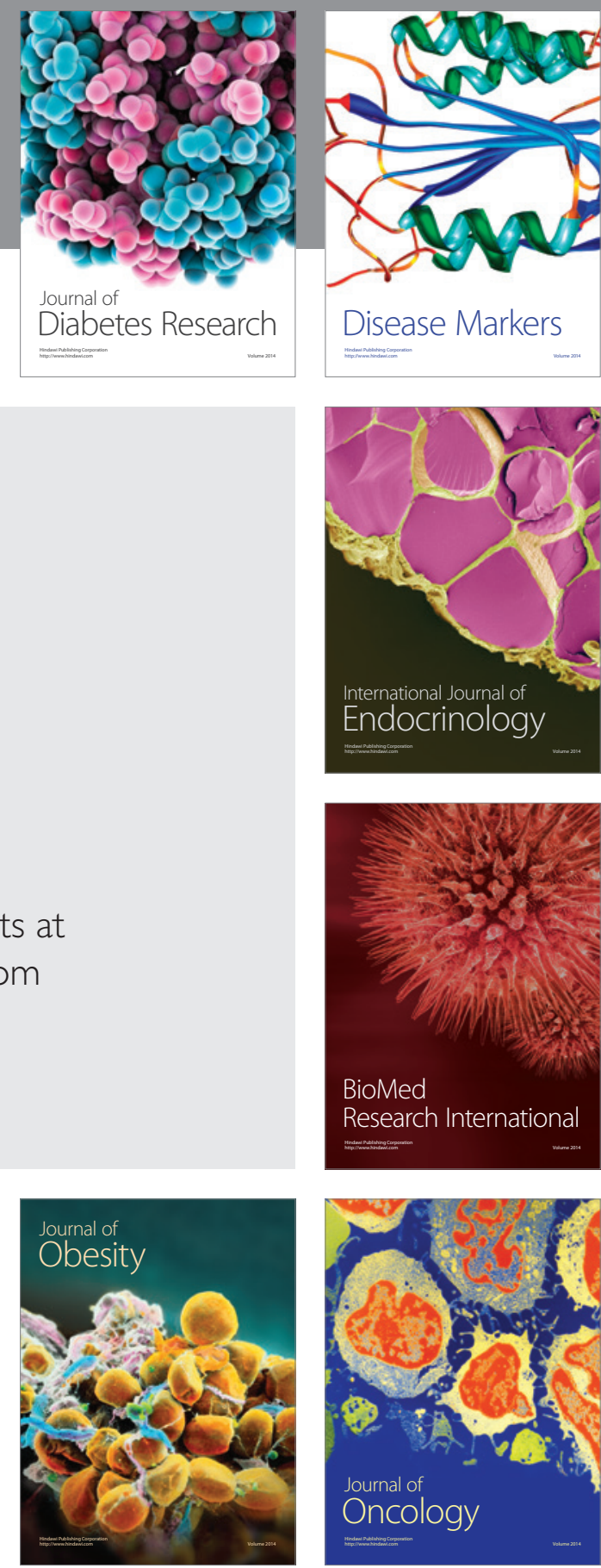

Disease Markers
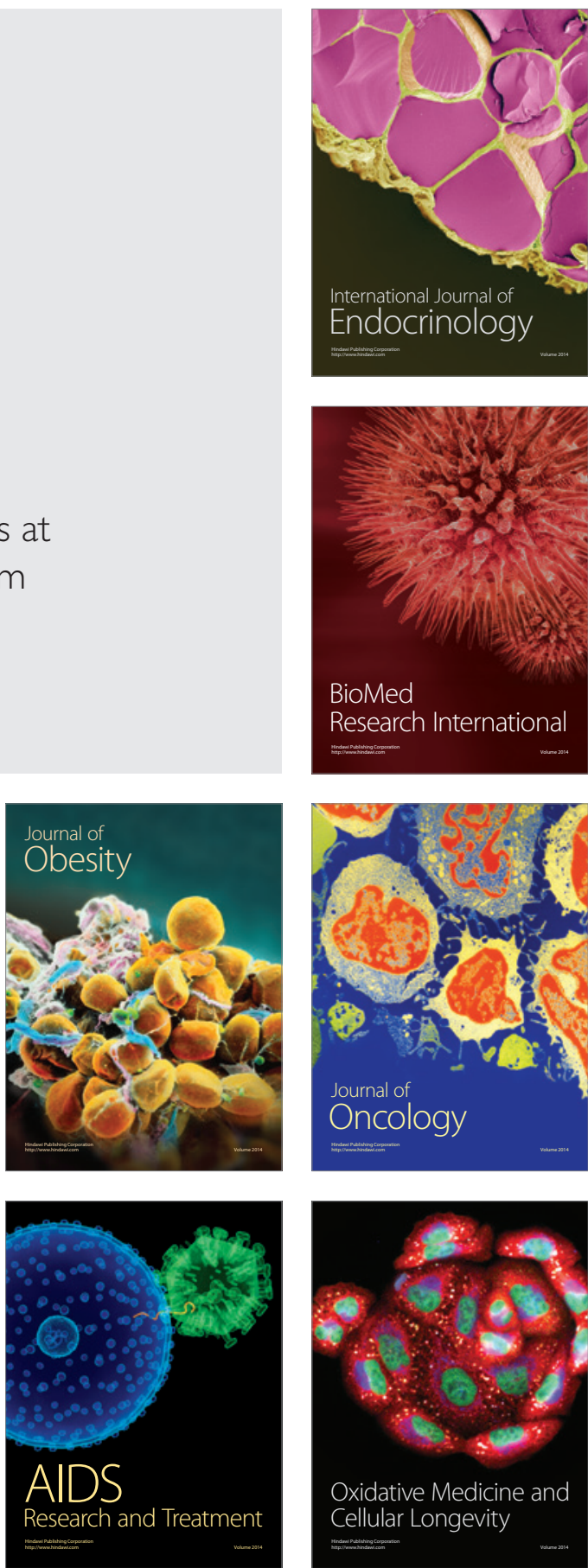